\title{
STUDY FOR IMPROVEMENT OF THE QUALITY OF CASTINGS IN AUTOMOBILE COMPONENTS PLANT BY USING SIX SIGMA TECHNIQUES
}

\author{
Umesh Bhatia \\ Department of Mechanical Engineering, \\ Acropolis Institute of Technology and Research, Indore, India \\ Manoj Modi, Veerandra Patil, Prakash Gawali, Mohit Shrotriya \\ Department of Mechanical Engineering, \\ Acropolis Institute of Technology and Research, Indore, India
}

\begin{abstract}
Casting is a manufacturing process in which a fluid material is filled a form, which contains an empty cavity of the ideal shape, and afterward permitted to solidify. The solidified part is known as a casting, which is shot out or broken out of the shape to finish the process. Casting materials are generally metals or different cold setting materials that fix subsequent to combining at least two parts; examples are epoxy, solid, mortar and dirt. Casting is regularly utilized for making intricate shapes that would be generally troublesome or uneconomical to make by different techniques.

We plan to study the existing percentage and type of defects among the castings manufactured in the plant of PORWAL AUTO COMPONENTS LTD (PACL). We will be using past six months of data available for the analysis. With the use of Root Cause Method (Pareto Analysis) we will analyze the data. With the help of quality control officials we shall go into the depth of the existing methods of manufacturing currently adopted and try to find out the exact cause of the defects occurring very frequently and in large numbers.

Pareto Analysis is a statistical technique in decisionmaking utilized for the determination of a predetermined number of assignments that produce critical generally impact. It utilizes the Pareto Principle (otherwise called the 80/20 guideline) the possibility that by doing $20 \%$ of the work you can create $80 \%$ of the advantage of doing the entire job.
\end{abstract}

Keywords: Casings, Casting defects, Cold Shut, Shrinkage, Shifting, Sand Drop, Mould, Shifting, Six Sigma, Pareto Analysis, Root Cause Analysis, Why-Why Analysis.

\section{INTRODUCTION}

Imperfections development in castings is one of the most vexed subjects of foundry ventures. Foundry businesses for the most part depend on various procedure boundaries to control such deformities guaranteeing high adequacy of projecting with an ideal yield consequently controlling of such boundaries gets vital by sound information on potential causes, for this the plausible imperfections ought to be broke down and their underlying drivers must be considered.

\subsection{About PACL}

PACL is engaged with assembling of an assortment of bendable iron, Gray cast iron steel and steel combination projecting parts and subassemblies. PACL obliges different divisions like car, building, siphons and valves, agribusiness and work vehicle parts, development gear, machine devices, railroads and so forth.

Their quality administration framework ISO 9001:2008 and ISO/TS 16949:2001 ensured by TUV NORD, likewise has RDSO endorsement for a class foundry to flexibly steel, CG, Gray iron projecting and parts for Indian Railway and plan to get accreditation for condition, wellbeing and security ISO 14001:2004 and OHSAS 18001:2007.

These are some products manufactured here

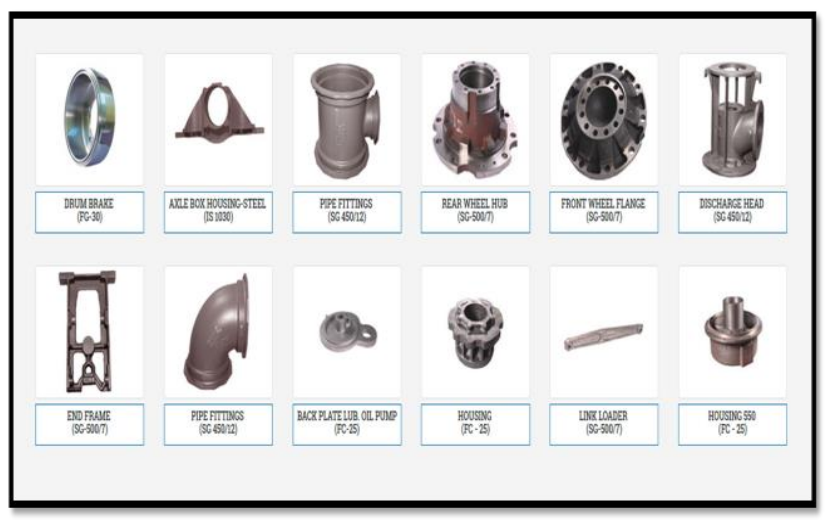

Figure 1.1 


\section{International Journal of Engineering Applied Sciences and Technology, 2020 \\ Vol. 5, Issue 4, ISSN No. 2455-2143, Pages 139-146 \\ Published Online August 2020 in IJEAST (http://www.ijeast.com)}

1.1 Basic concepts of foundry

A foundry is a manufacturing plant that produces metal castings. Metals are projected into shapes by dissolving them into a fluid, pouring the metal in a form, and eliminating the form material or projecting after the metal has set as it cools. The most widely recognized metals prepared are aluminum and solid metal. Nonetheless, different metals, for example, bronze, metal, steel, magnesium, and zinc, are additionally used to create castings in foundries. In this cycle, portions of wanted shapes and sizes can be framed.

\section{Process of foundry is as follows:}

\section{Melting}

Dissolving is done in a heater. Virgin material, outside piece, inward piece, and alloying components are utilized to charge the heater. Virgin material alludes to industrially unadulterated types of the essential metal used to frame a specific combination. Alloying components are either unadulterated types of an alloying component, similar to electrolytic nickel, or amalgams of restricted structure, for example, ferroalloys or ace combinations. Outer piece is material from other shaping cycles, for example, punching, fashioning, or machining. Inner piece comprises of entryways, risers, imperfect castings, and different unessential metal oddments created inside the office.

\section{Mold making}

In the projecting cycle an example is made looking like the ideal part. Straightforward plans can be made in a solitary piece or strong example. More mind boggling plans are made in two sections, called split examples. A split example has a top or upper segment, called an adapt, and a base or lower segment called a drag. Both strong and split examples can have centers embedded to finish the last part shape. Centers are utilized to make empty regions in the shape that would somehow or another be difficult to accomplish. Where the adapt and drag isolates is known as the splitting line.

When making an example it is ideal to tighten the edges so the example can be taken out without thinking outside the box. This is called draft. Something contrary to draft is an undermined where there is essential for the example under the shape material, making it difficult to eliminate the example without harming the form.

The example is made out of wax, wood, plastic, or metal. The molds are built by a few distinct cycles subordinate upon the kind of foundry, metal to be poured, amount of parts to be created, size of the projecting, and multifaceted nature of the projecting. These shape measures include:

- Sand projecting - Green or sap fortified sand form.

- Lost-froth projecting — Polystyrene design with a blend of fired and sand shape.

- Investment projecting - Wax or comparative conciliatory example with a fired shape.

- Ceramic shape projecting — Plaster form.
- V-measure projecting — Vacuum with thermoformed plastic to shape sand molds. No dampness, earth or pitch required.

- Die projecting - Metal form.

- Billet (ingot) projecting - Simple form for delivering ingots of metal, regularly for use in different foundries.

\section{Pouring}

In a foundry, liquid metal is filled molds. Pouring can be practiced with gravity, or it might be helped with a vacuum or pressurized gas. Numerous advanced foundries use robots or programmed pouring machines to pour liquid metal. Generally, molds were poured by hand utilizing spoons.

\section{Shakeout}

The solidified metal part is then eliminated from its shape. Where the form is sand based, this should be possible by shaking or tumbling. This liberates the projecting from the sand, which is as yet appended to the metal sprinters and doors - which are the channels through which the liquid metal went to arrive at the part itself.

\section{Degating}

Degating is the evacuation of the heads, sprinters, doors, and risers from the projecting. Sprinters, doors, and risers might be taken out utilizing cutting lights, bandsaws, or fired cutoff edges. For some metal sorts, and with some gating framework structures, the sprue, sprinters, and entryways can be eliminated by splitting them away from the projecting with a sledge hammer or uncommonly planned knockout hardware. Risers should generally be eliminated utilizing a cutting strategy (see above) however some more up to date techniques for riser evacuation use knockoff hardware with exceptional plans joined into the riser neck math that permit the riser to sever at the opportune spot.

The gating framework is needed to create castings in a form yields extra metal - including heads, risers, and sprue (some of the time all things considered called sprue) - that can surpass half of the metal needed to pour a full shape. Since this metal must be remelted as rescue, the yield of a specific gating setup turns into a significant monetary thought when planning different gating plans, to limit the expense of overabundance sprue, and hence generally speaking softening expenses.

\section{Heat treating}

Heat treating is a gathering of modern and metalworking measures used to change the physical, and now and then concoction, properties of a material. The most well-known application is metallurgical. Warmth medicines are likewise utilized in the production of numerous different materials, for example, glass. Warmth treatment includes the utilization of warming or chilling, typically to extraordinary temperatures, to accomplish an ideal outcome, for example, solidifying or 


\section{International Journal of Engineering Applied Sciences and Technology, 2020 \\ Vol. 5, Issue 4, ISSN No. 2455-2143, Pages 139-146 \\ Published Online August 2020 in IJEAST (http://www.ijeast.com)}

mellowing of a material. Warmth treatment procedures incorporate toughening, case solidifying, precipitation fortifying, hardening, and extinguishing. It is vital that while the expression "heat treatment" applies just to measures where the warming and cooling are accomplished for the particular motivation behind modifying properties purposefully, warming and cooling regularly happen unexpectedly during other assembling cycles, for example, hot framing or welding.

\section{Surface cleaning}

In the wake of degating and warmth treating, sand or other embellishment media may remain clung to the projecting. To eliminate any form leftovers, the surface is cleaned utilizing an impacting cycle. This implies a granular media will be impelled against the outside of the projecting to precisely thump away the following sand. The media might be blown with compacted air, or might be flung utilizing a shot wheel. The cleaning media strikes the projecting surface at high speed to unstick the form remainders (for instance, sand, slag) from the projecting surface. Various materials might be utilized to clean project surfaces, including steel, iron, other metal composites, aluminum oxides, glass dabs, pecan shells, heating powder, and numerous others. The impacting media is chosen to build up the shading and reflectance of the cast surface. Terms used to portray this cycle incorporate cleaning, dot impacting, and sand impacting. Shot peening might be utilized to additionally work-solidify and finish the surface.

\section{Finishing}

The final step in the process of casting usually involves grinding, sanding, or machining the component so as to accomplish the ideal dimensional exactnesses, physical shape, and surface finish.

\subsection{DEFECTS}

According to the QC department of PACL the major defects that are seen in the castings are classified as follows:

1. Cold Shut: The freezing of the surface of liquid metal during the pouring of an ingot or casting due to interrupted or improper pouring.

2. MR (metal rejection): If the metal used for casting is not proper according to the requirements then the defect is listed under MR or metal rejection.

3. Shrinkage: If the casting loses its shape and properties due to the shrinkage of metal on cooling then the defect is listed under shrinkage.

4. Slag

5. Short Pour: If the melted metal does not reach the corners of the mold and then solidifies the casting is not of proper shape. This maybe because of the metal being cooler than required or improper gating and channeling in the mold.

6. Sand Drop: This defect occurs when while pouring the metal the sand at the walls of the mold erodes and as a result the surface of the casting is below the required quality.

7. Mould Broken

8. Box Lift: If the casting gets defected while moving out of the box after cooling of the casting.

9. Scabbing: Scabs are a thin layer of metal that sits proud of the casting. When removed they reveal an indentation in the casting surface.

10. Shifting

11. Leakage

12. Blow Hole: If gases are trapped inside the mould while pouring the metal the gases trying to escape leave a path behind them in the form of a hole in the casting

13. DBR (decoring broken)

14. NBR (knockout broken)

15. Overgrinding

16. LT (less thickness)

17. Core Broken

18. Crack

19. Others

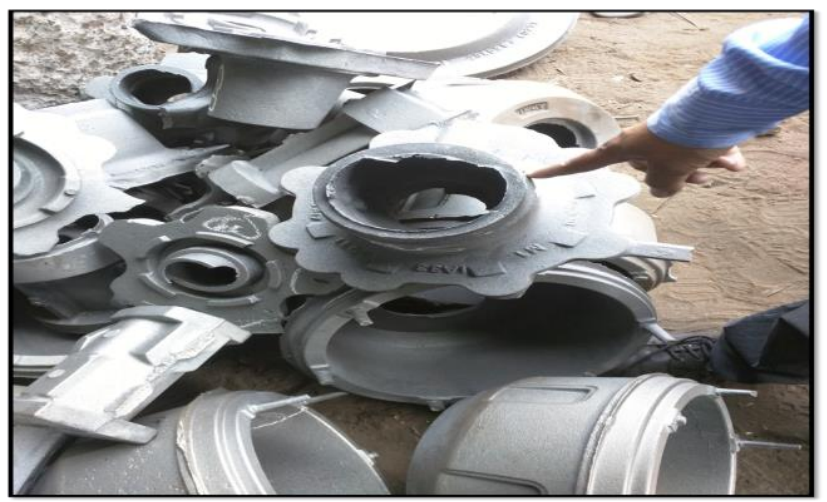

Figure 1.2

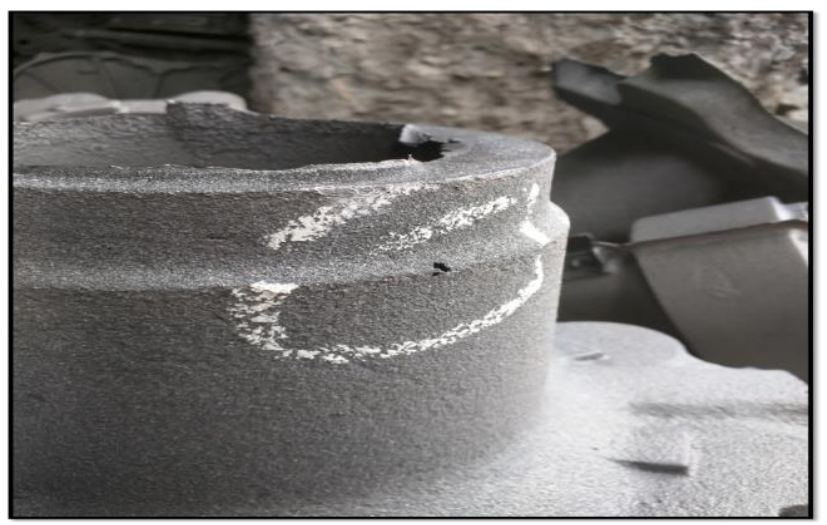

Figure 1.3 
International Journal of Engineering Applied Sciences and Technology, 2020

Vol. 5, Issue 4, ISSN No. 2455-2143, Pages 139-146

Published Online August 2020 in IJEAST (http://www.ijeast.com)

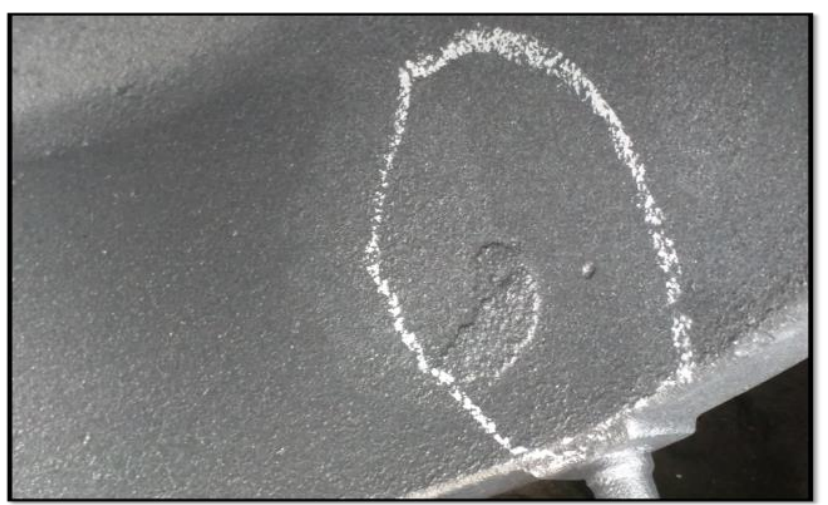

Figure 1.4

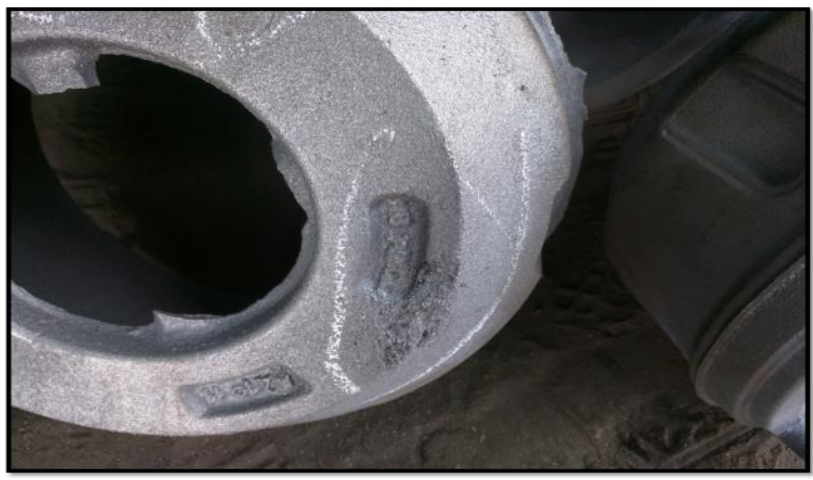

Figure 1.5

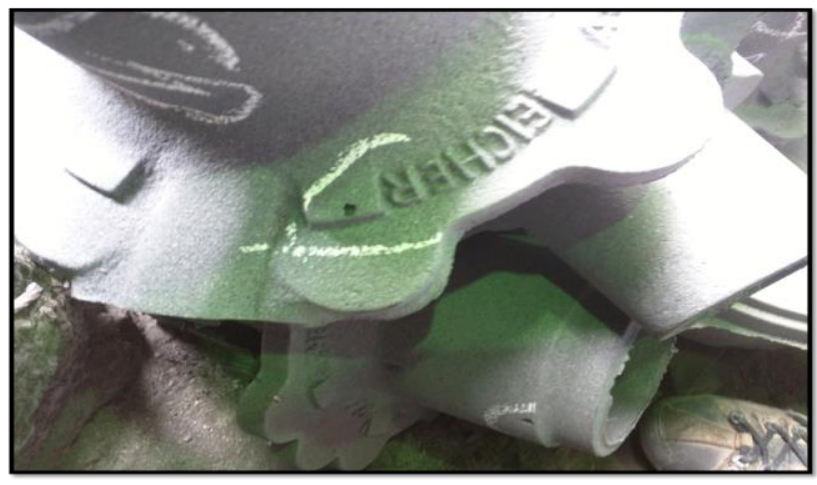

Figure1.6

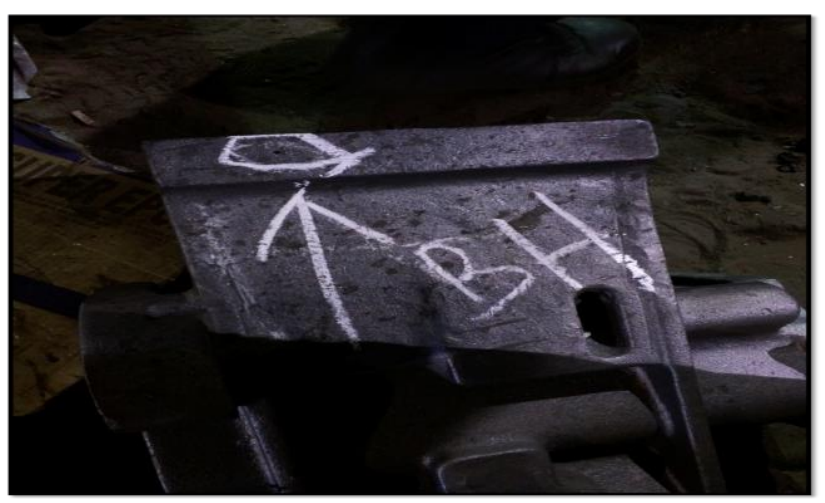

Figure 1.7

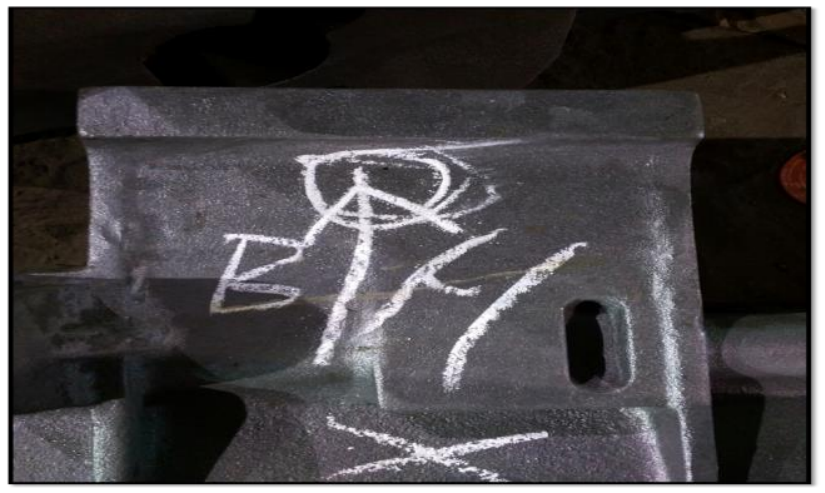

Figure1.8

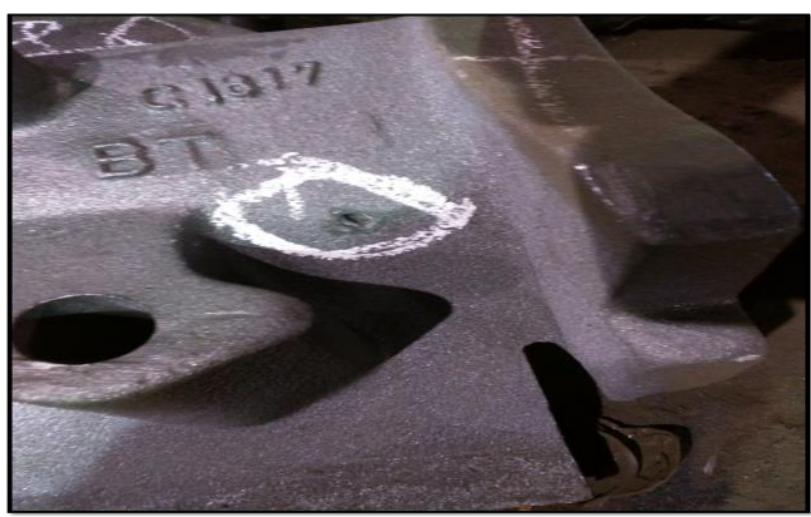

Figure 1.9

\section{PROBLEM DEFINITION}

Study the various types of defects in casting being manufactured. We also wanted to use the six sigma techniques to analyze the defects, identify the causes and suggest remedial actions so as to reduce rate of rejections in order to improve the quality of the castings.

\section{METHODOLOGY}

3.1 Data Collection 


\section{International Journal of Engineering Applied Sciences and Technology, 2020 \\ Vol. 5, Issue 4, ISSN No. 2455-2143, Pages 139-146 \\ Published Online August 2020 in IJEAST (http://www.ijeast.com)}

The data relevant to the analysis was collected from the access files that were made by the PACL officials. The selection of relevant data and sorting of it was a behemoth task which required a lot of time but at the end was completed successfully. We separated 6 months worth data for a few major components and proceeded with the analysis. The data collected was as recent as possible i.e. October 2016 to March 2017.

\subsection{Data Compilation}

Following tables and graphs were prepared after compiling the data:

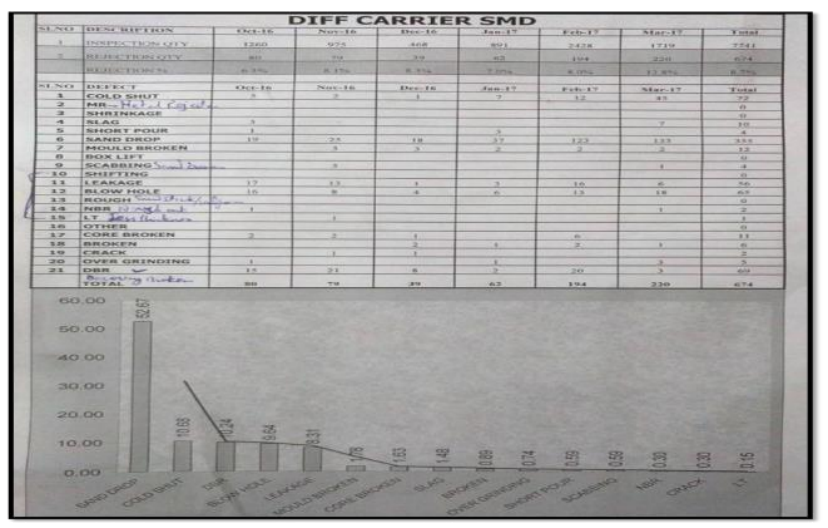

Figure 3. 1

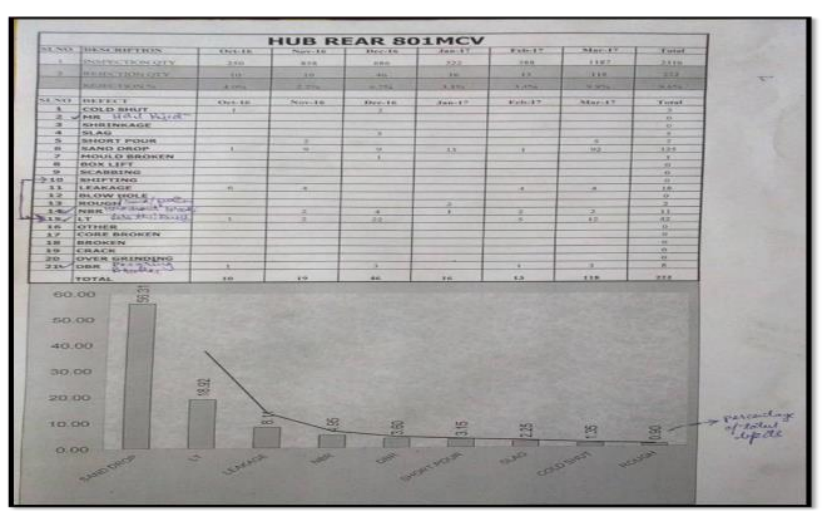

Figure 3.2

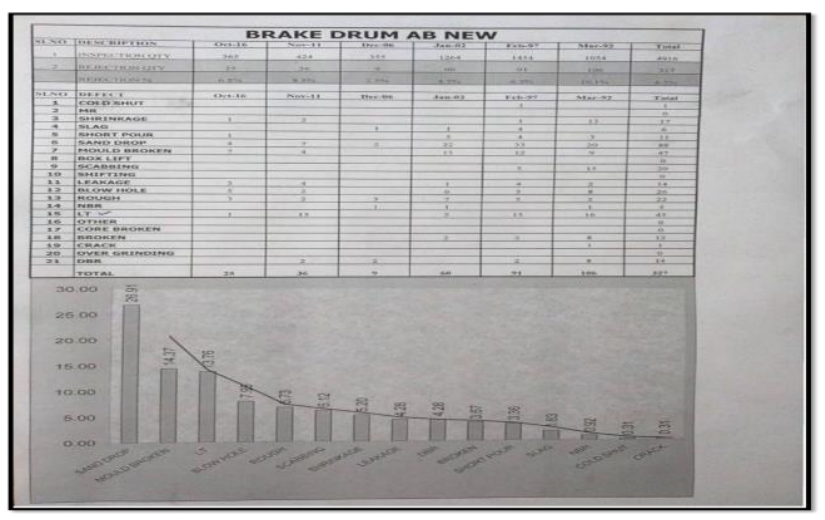

Figure 3. 3

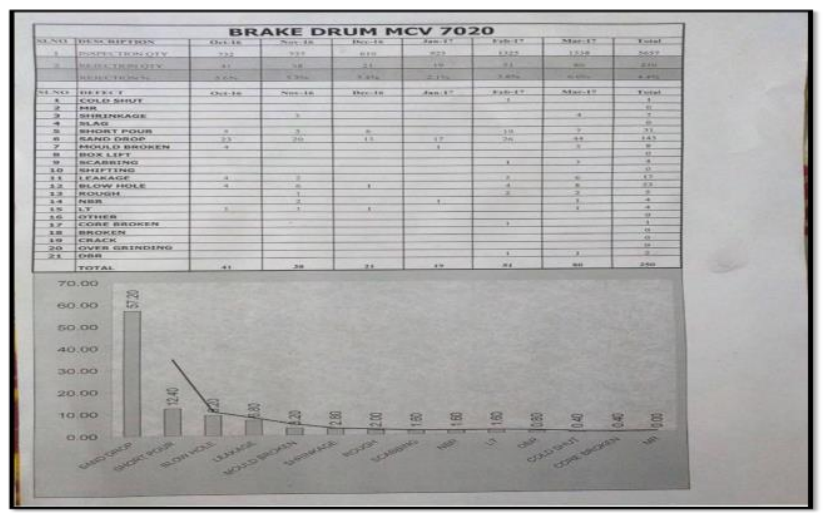

Figure 3. 4

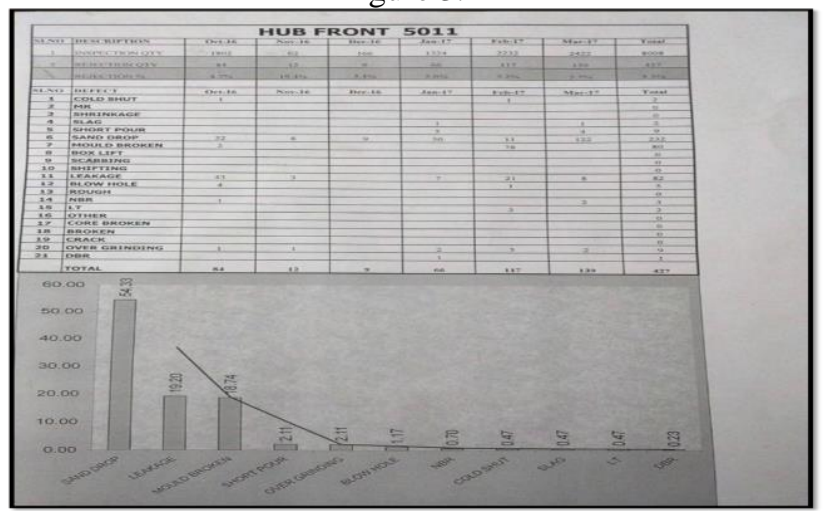

Figure 3.5

Current sigma level

To find the current sigma level at which PACI works following steps were taken:

Step 1: Define Your Opportunities. An opportunity is the lowest defect noticeable by a customer.

Step 2: Define Your Defects.

Step 3: Measure Your Opportunities and Defects.

Step 4: Calculate Your Yield.

Step 5: Look Up Process Sigma

For the data used the no of opportunities are: 28,638

For the data used the no of defects are $\quad: 1,900$ 


\section{International Journal of Engineering Applied Sciences and Technology, 2020 \\ Vol. 5, Issue 4, ISSN No. 2455-2143, Pages 139-146 \\ Published Online August 2020 in IJEAST (http://www.ijeast.com)}

The process yield is calculated by subtracting the total number of defects from the total number of opportunities, dividing by the total number of opportunities, and finally multiplying the result by 100 .

$$
\begin{aligned}
\text { Process Yield } & =\frac{(28638-1900) * 100}{28638} \\
& =93.37 \%
\end{aligned}
$$

Defect percentage $=6.63 \%$

DPMO (Defects parts per milliom) $=66345$

Using Six Sigma conversion table, we checked

Process sigma $=3$

\subsection{Pareto analysis}

Pareto Analysis is a statistical technique in decision-making used for the selection of a limited number of tasks that produce significant overall effect. It uses the Pareto Principle (also known as the 80/20 rule) the idea that by doing $20 \%$ of the work you can generate $80 \%$ of the benefit of doing the entire job.

These are the following results of Pareto Analysis performed

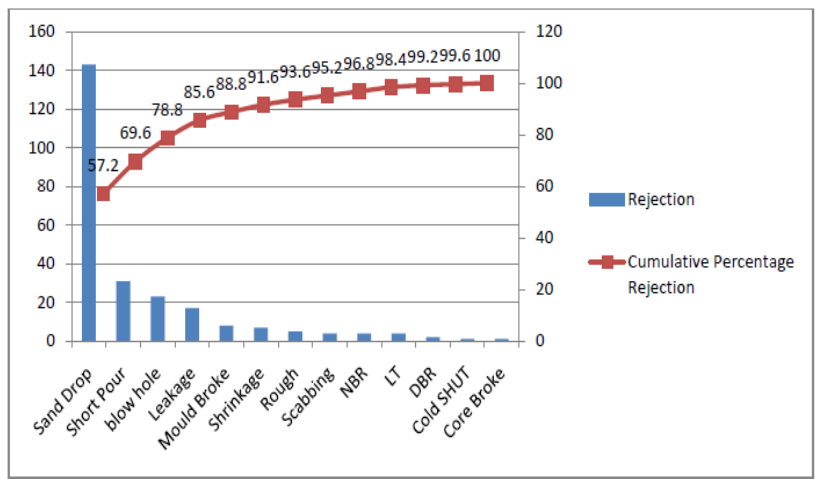

Brake Drum MCV Pareto Analysis

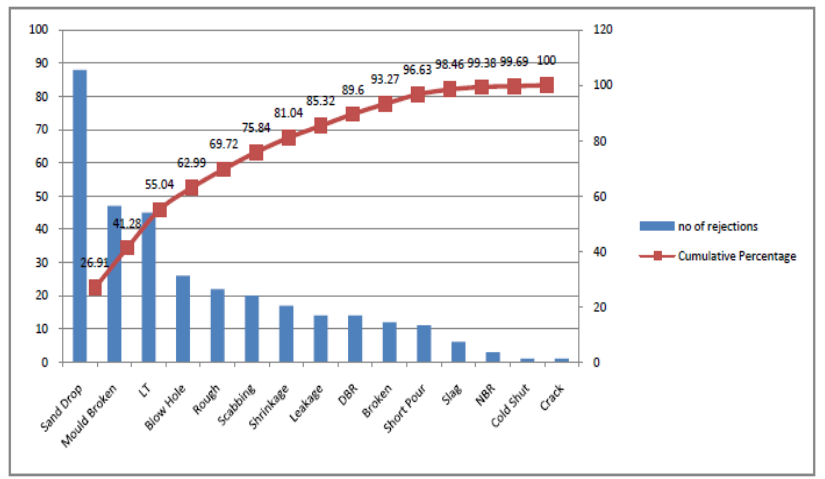

Brake Drum AB Pareto

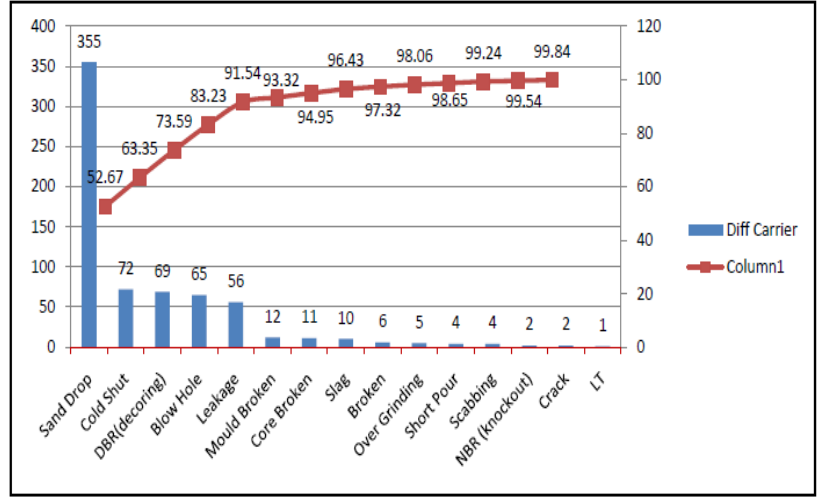

Diff Carrier SMD

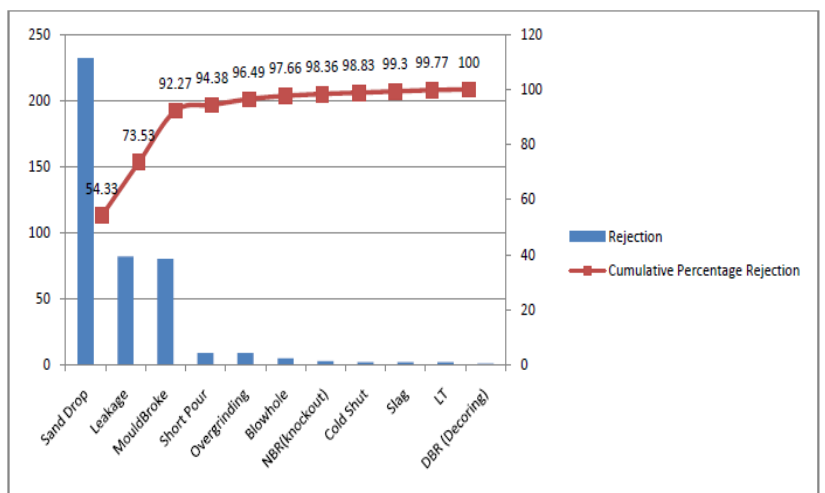

Hub Front Pareto

3.3Root cause analysis

Root cause analysis (RCA) is a deliberate cycle for distinguishing "root causes" of issues or occasions and a methodology for reacting to them. RCA depends on the fundamental thought that compelling administration requires more than just "extinguishing fires" for issues that grow, however figuring out how to forestall them.

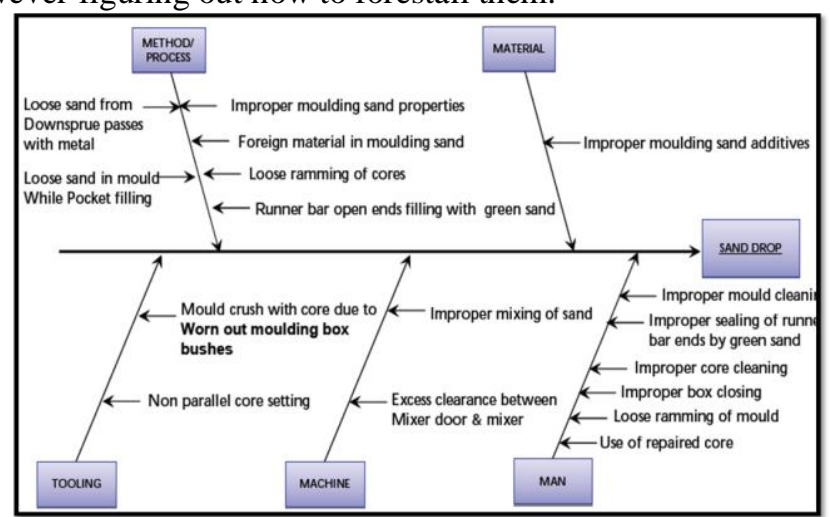

Figure 3.6

3.4 Why-why analysis

It is a technique for scrutinizing that prompts the recognizable proof of the root cause(s) of an issue. A significant part of main driver examination is an exhaustive comprehension of "what occurred". The group starts by auditing an "underlying 


\section{International Journal of Engineering Applied Sciences and Technology, 2020 \\ Vol. 5, Issue 4, ISSN No. 2455-2143, Pages 139-146 \\ Published Online August 2020 in IJEAST (http://www.ijeast.com)}

comprehension" of the occasion and distinguishing unanswered inquiries and data holes. The Informationgathering measure incorporates interviews with staffs and laborers who were legitimately and in a roundabout way engaged with the physical condition where the occasion and other important cycles occurred, alongside perception of regular work measures. This data is incorporated into a "last understanding", which is additionally utilized by the group to start the "why" segment of the examination in a legitimate succession to locate a coherent answer for the issue. It is one of the many conceptualizing technique of asking "why" multiple times consistently to help in recognizing the main driver of an issue. On the off chance that an issue is over and again addressed, each time an elective arrangement comes out which is connected to the underlying driver. Be that as it may, inquiring as to for what reason might be proceeded till getting a pleasing arrangement. Five is a discretionary figure.

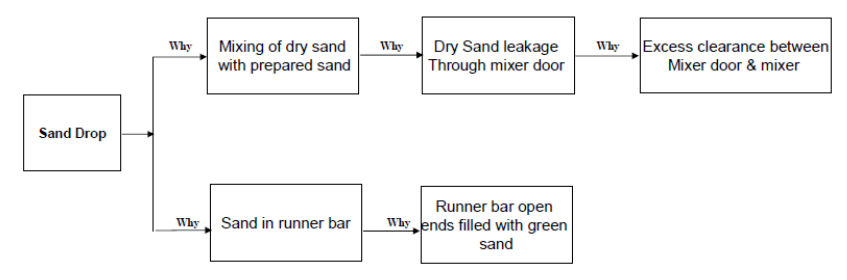

3.5 Final solution selection

\begin{tabular}{|l|l|l|}
\hline S. No. & Causes & Possible Solution \\
\hline 1 & $\begin{array}{l}\text { Excess clearance } \\
\text { between mixer and } \\
\text { mixer door }\end{array}$ & $\begin{array}{l}\text { Mixer door adjustment to } \\
\text { reduce excess clearance } \\
\text { between mixer and mixer } \\
\text { door. }\end{array}$ \\
\hline 2 & $\begin{array}{l}\text { Sand in Runner } \\
\text { bars }\end{array}$ & $\begin{array}{l}\text { Plugging and sealing of } \\
\text { runner bar open ends by } \\
\text { cold box core piece. }\end{array}$ \\
\hline
\end{tabular}

IV. OBSERVATIONS AND CONCLUSIONS

The above work was a systematic approach towards improving quality by minimizing rejections in casting.

Detailed study was made on casting defects in Differential Carrier, Hubs Rear, Brake drum, Hub Front being casted.

Paretto analysis, Root Cause analysis, Why-Why analysis of six sigma were used in this research work. It was observed that out of most common occurring defects, Sand drop defect was major rejection i.e. $53 \%$ to 59\%. Root cause for San Drop defect was due to Excess clearance between Mixer \& Mixer door And Sand in Runner passage.

Remedial actions to improve san drop defects in casting are:

1) Rectify Mixer door to minimize clearance.

2) Plugging and Sealing of runner open ends by cold box core piece.

\section{REFERENCES}

[1] Jaglan, P. (2011). Six Sigma: A Road Map for SMEs Research Scholar, Mechanical Department, NIT, Kuruksetra.

[2] Porter, L. (2001). Six Sigma excellence. Quality Word, (pp. 112-115).

[3] Eckes, G. (2001). The Six Sigma Revolution. NY: Wiley.

[4] Anderson, B., and Fagerhaug, T., (2000). Root Cause Analysis: Simplified Tools and Techniques. Milwaukee: ASQ Quality Press.

[5] Arcaro, J. S. (1997). TQM Facilitator's Guide. Boca Raton, FL: St. Lucie Press.

[6] Dean, L.G. (2007). Comparison of Common Root Cause Analysis Tools and Methods. Apollo Root Cause Analysis - A new way of Thinking, 3rd Edition

[7] Duggett, A. M. (2004). A statistical Comparison of Three Root Cause Tools. Journal of Industrial Technology, Vol. 20(2), (pp.1-9).

[8] Moran, J. W., Talbot, R. P., and Benson, R. M. (1990). A Guide to Graphical Problem-Solving Processes. Milwaukee: ASQC Quality Press.

[9] Robson, M. (1993). Problem Solving In Groups. (2 ${ }^{\text {nd }}$ ed.), Brookfield, VT: Gower

[10] American Foundrymen Association (1947), Analysis of Casting Defects.

[11] Modi, M., Agarwal, G., Patil, V., Bhatia, U., and Pancholi, R. (2019). Parametric optimization in Drilling of $\mathrm{Al} / \mathrm{SiC}$ composite using Taguchi Method, International Journal of Scientific \& Technology Research, Vol. 8 (9), (pp.2019-22),

http://www.ijstr.org/finalprint/sep2019/Parametric Optimization-In-Drilling-OfAlsic-Composite-UsingTaguchi-Method.pdf.

[12] Modi, M., Agarwal, G., Patil, V., Khare, A., Shukla, S., and Shankhla, A. (2019). Modeling and Analysis of Turning Process on Lathe Machine by Taguchi and ANOVA Approach, International Journal of Scientific \& Technology Research, Vol. 8(10),(pp.1466-70), http://www.ijstr.org/final-print/oct2019/ModelingAndAnalysis-Of-Turning-Process-On-Lathe-MachineByTaguchi-And-Anova-Approach.pdf.

[13] Modi, M., Agarwal, G., Chaugaonkar, S.D., Bhatia, U., and Patil, V. (2020). Effect of Machine Feed Rate on Kerf-Width, Material Removal Rate, and Surface Roughness in Machining of $\mathrm{Al} / \mathrm{SiC}$ Composite Material with Wire Electrical Discharge Machine,Strojnícky časopis-Journal of Mechanical Engineering, Vol. 70 (1), (pp.81-88), DOI: 10.2478/scjme-2020-0008.

[14] Modi, M., Agarwal, G. (2012). Design, Development \& Experimental Investigation of Electro-Discharge Diamond Surface Grinding of Ti-6Al-4V. International Journal of Advanced Materials Research, vol. 418- 420, (pp. 1478-1481), DOI:10.4028/www.scientific.net/ AMR.418-420.1478.

[15] Beeley, P. R., (2001). Foundry Technology, Butterworth. 
International Journal of Engineering Applied Sciences and Technology, 2020 Vol. 5, Issue 4, ISSN No. 2455-2143, Pages 139-146

Published Online August 2020 in IJEAST (http://www.ijeast.com)

[16] Ramana Rao, T. V. (1996). Metal casting Principles and Practice, New Age International Private Limited. 